\title{
Iron Deficiency Anemia (IDA) in Pregnant Women of Different Ages in Swat District, Khyber Pakhtunkhwa Pakistan
}

\author{
Atta Ullah ${ }^{1, *}$, Ali Muhammad Yousafzai ${ }^{1}$, Gul Nabi Khan ${ }^{1,2}$, Nasir Iqbal ${ }^{3}$, Bashir Ahmad ${ }^{1}$ \\ 1. Department of Zoology, Islamia College University Peshawar, Peshawar 25120, Pakistan \\ 2. Department of Life Science and Biotechnology, Korea University, Seoul 02841, South Korea \\ 3. Department of Chemistry, Jahanzeb College, Saidu Sharif Swat, Pakistan. \\ *Corresponding Author: Email address: attakhan_154@yahoo.com; \\ Phone NO: 00923469693947; Fax No: 818001
}

\begin{abstract}
The aim of this study was to find out the incidence of anemia in pregnant women of Swat District; to analyze the iron variations and its dietary effects.Data were collected during the periods of January - September 2016. The study of samples comprised of 250 pregnant women in the different trimester. Blood sample from each woman was collected and full blood count (FBC) was conducted through Mindray BC-3000 plus hem analyzer for all pregnant individuals. Confirmed anemic cases were then examined for IDA with serum ferritin, serum iron, total iron binding capacity (TIBC) through Randox kit and serum transferrin saturation was estimated by formula (serum ferritin saturation $=$ serum iron $\times 100 /$ TIBC). The total number of participants in the first trimester were 50, among them 26 women were suffer from iron deficiency anemia (IDA) with $52 \%$ weightage of prevalence rate, (mean $\mathrm{Hb}$ concentration $9.602 \pm 0.87 \mathrm{~g} / \mathrm{dl}$ ). The rates of IDA were 63.3\%; ( mean $\mathrm{Hb}$ concentration $8.48 \pm 1.24 \mathrm{~g} / \mathrm{dl}$ ) and 54\%; ( mean $\mathrm{Hb}$ concentration $9.18 \pm 1.28 \mathrm{~g} / \mathrm{dl}$ ), among 150 and 50 participants in the second and third trimester, respectively. A significant correlation was found between serum ferritin and $\mathrm{Hb}$, serum ferritin against $\mathrm{MCV}$ and serum ferritin against $\mathrm{MCH}$. The high prevalence of anemia was found $78.2 \%$ in the age group from $26-30$ followed by $78.2 \%$ in the age group 36-40 years compared to those of other age groups in the second trimester. In this study the prevalence of IDA in third trimester is lower compared to first and second trimester.
\end{abstract}


Keywords: anemia; iron deficiency; pregnancy; serum ferritin; mean corpuscular volume (mcv); mean corpuscular hemoglobin (MCH); Northern Pakistan

\section{Introduction}

Iron is a vital constituent of blood hemoglobin, which carries oxygen from the respiratory organ to the rest of the body. Iron is essential for the normal biological activities, including DNA synthesis, respiration, and cell division [1]. Hemoglobin below $11 \mathrm{~g} / \mathrm{dL}$ during pregnancy is considered abnormal and anemia can be observed due to iron deficiency (ID) [2]. ID is the most globally nutritional problem and is considered at epidemic level in many developing countries [3]. About 50\% of ID cases are reported due to the insufficient iron uptake during pregnancy [4]. Due to fetal growth, need for iron supplementation rises in the second and third period. To meet this increased iron demand fascination in the gut is not adequate. Therefore, iron equilibrium depends on parental iron stocks throughout these stages [5]. The incidence of anemia in developed countries is $9 \%$ compared to $43 \%$ in developing countries [6].Anemia in early prenatal period has been related with adverse pregnancy outcomes [7]. Most common symptoms of iron deficiency anemia (IDA) are fatigue, fainting and difficulty in breathing [4]. Anemia is usually noticed in teenager mothers due to their unplanned pregnancies and the suboptimal nutrition status [8]. Infant and young children suffer from anemia are at high risk of developmental abnormalities like cognitive, social emotional and adoptive functions [9]. Prevalence of anemia is higher in those pregnant women who belong to low socioeconomic status in many parts of the world [10]. While the other group of women is teenager mothers who face high risk to their health and realize greater nutritional requirements [11]. The current study described, that nutritional deficiencies at beginning and throughout the primary prenatal period may impact the result of the pregnancy. Moreover, pregnancy at teenage must need the required diet for mother health in addition to the nutritional desires during gestation. In addition, women belong to low income families are commonly at more risk due to insufficient intake of balanced food. The main cause of anemia is heavy bleeding during menstrual cycle and its effect is 
found in 9-14\% women [12] During pregnancy the increase in demand of iron occurs which leads to, increase in iron binding capacity and serum transferrin level rises [13].

\section{Material and methods}

\subsection{Study area}

The study was conducted in Swat District, Khyber Pakhtunkhwa (K P), Pakistan. Two maternity health clinics, Sabeel Surgical and Maternity Home (the study clinic), Shifa hospital (the control clinic) in the Saidu Sharif Swat were selected for data collection in this study.

\subsection{Study Population}

The study contributors were mainly pregnant women. All women at pregnancy were registered for antenatal health care at the maternal health Centre within the study periods for better counseling served as the study population.

\subsection{Data collection}

Two hundred and fifty clinically positive pregnancy cases from age 16 to 45 years nominated from the Swat District. Complete history collected from each patient were analyze in this study.

The study of samples comprised of 250 pregnant women in the all trimester (Total 250 cases; out of which 50 are in the $1^{\text {st }}$ trimester, 150 in $2^{\text {nd }}$ trimester and 50 cases are in the $3^{\text {rd }}$ trimesters) classified in to different age groups. Data were collected during the period since Jan to Sep, 2016.

\subsection{Blood test}

Blood sample from each woman was collected and full blood count (FBC) was conducted through Mindray BC-3000 plus hem analyzer for all pregnant individuals. Confirmed anemic 
individual were then examined for IDA with serum ferritin, serum iron, total iron binding capacity (TIBC) through Randox kit and serum transferrin saturation was estimated by formula (serum ferritin saturation $=$ serum iron $\times 100 /$ TIBC).

\subsection{Statistical analysis}

All experimental results were examined by statistical package for social sciences (SPSS) software database. Observations were considered statistically significant at $\mathrm{P}<0.05$ ). Scatter plots were also constructed for the serum ferritin against $\mathrm{Hb}$, serum ferritin against $\mathrm{MCV}$ and serum ferritin against $\mathrm{MCH}$.

\subsection{Ethical considerations}

To conduct this study, permission was taken from the MS of Sabeel Surgical and Maternity Home Swat. All patients were informed that data will be used for investigation purposes.

\section{Result}

Data shown in (table 1) represents the occurrence of IDA during first trimester in different age groups of studied population. Among 50 patients 26 were found anemic which constitutes $52 \%$ of the sample size. The proportion of anemic patients were found; 12.6, 9.3, 5, $10.6,8.4$ and $5.6 \%$ in age groups $16-20,21-25,26-30,31-35,36-40$ and $41-45$ respectiviely. The highest number of anemic patients was found in age group16-20, while the lowest number was found in 21-25 group of population. Differences in the incidence value amongst different age groups in the first trimester were not statistically significant $(P=0.32)$. In the second trimester among 150 participants 95 were found anemic which constitutes $63.3 \%$ of the sample size. The percentage of anemic patients were; $13.2,7.1,14,11.4,14$, and $3.6 \%$ in age groups, 16-20, 21 $25,26-30,31-35,36-40$ and 41-45, respectively, in population. The maximum number of patients was observed in age group 26-30, while the least number of anemic patients were in age group 41-45. Differences in the incidence value amongst the different age groups in the second trimester were statistically significant $(P=0.00)$. Occurrence of IDA during third trimester, out 
of 50 participants 27 were found anemic which constitutes $54 \%$ of the sample size for the third trimester. The percent number of anemic patients in third trimester were, 11.5, 10.3, 5.8, 9.2, 10.8 and $6 \%$ in age groups, 16-20, 21-25, 26-30, 31-35, 36-40 and 41-45, respectively, in population. Differences in the incidence value amongst the different age groups in the third trimester were not statistically significant $(P=0.082)$. The lowest occurrence was observed in the first trimester $(52 \%$; mean $\mathrm{Hb}$ concentration $9.602 \pm 0.87 \mathrm{~g} / \mathrm{dl})$, the high incidence were found in the second trimester (63\%; mean Hb concentration $8.48 \pm 1,24 \mathrm{~g} / \mathrm{dl})$, while in the third trimester (54\%; mean $\mathrm{Hb}$ concentration $9.18 \pm 1.28 \mathrm{~g} / \mathrm{dl}$ ). The mean, $\mathrm{SD}$ of all $\mathrm{Hb}$, serum ferritin, serum iron, TIBC, transferrin saturation, $\mathrm{MCV}$ and $\mathrm{MCH}$ were calculated (See table 2). For the correlation study scatter plots of serum ferritin against $\mathrm{Hb}$, serum ferritin against $\mathrm{MCV}$ and serum ferritin against MCH were drawn and found statistically significant (Fig1, 2 and 3).

Table 1 shows percent anemic contributions in individual age group wise and total in population.

\begin{tabular}{|l|l|l|l|l|l|l|l|l|l|l|l|l|l|}
\hline $\begin{array}{l}\text { Age group } \\
\text { (years) }\end{array}$ & \multicolumn{2}{|l|}{$\begin{array}{l}\text { No. of cases } \\
\text { patient }\end{array}$} & \multicolumn{2}{|l|}{$\begin{array}{l}\text { No. of anemic } \\
\text { Trimester }\end{array}$} & \multicolumn{2}{|l|}{$\begin{array}{l}\text { Anemic percentage in } \\
\text { individual age groups }\end{array}$} & \multicolumn{2}{l}{$\begin{array}{l}\text { Anemic percentage in } \\
\text { total }\end{array}$} \\
& $1^{\text {st }}$ & $2^{\text {nd }}$ & $3^{\text {rd }}$ & $1^{\text {st }}$ & $2^{\text {nd }}$ & $3^{\text {rd }}$ & $1^{\text {st }}$ & $2^{\text {nd }}$ & $3^{\text {rd }}$ & $1^{\text {st }}$ & $2^{\text {nd }}$ & $3^{\text {rd }}$ \\
\hline $16-20$ & 8 & 11 & 7 & 6 & 8 & 5 & $75 \%$ & $72 \%$ & $71.4 \%$ & $12.6 \%$ & $13.2 \%$ & $11.5 \%$ \\
\hline $21-25$ & 9 & 28 & 11 & 5 & 11 & 7 & $55 . \%$ & $39.2 \%$ & $63.6 \%$ & $9.3 \%$ & $7.1 \%$ & $10.3 \%$ \\
\hline $26-30$ & 10 & 46 & 11 & 3 & 36 & 4 & $30 \%$ & $78.2 \%$ & $36.3 \%$ & $5 \%$ & $14 \%$ & $5.8 \%$ \\
\hline $31-35$ & 11 & 32 & 7 & 7 & 20 & 4 & $63 . \%$ & $62.5 \%$ & $57 \%$ & $10.6 \%$ & $11.4 \%$ & $9.2 \%$ \\
\hline $36-40$ & 6 & 23 & 6 & 3 & 18 & 4 & $50 \%$ & $78.2 \%$ & $66.6 \%$ & $8.4 \%$ & $14 \%$ & $10.8 \%$ \\
\hline $41-45$ & 6 & 10 & 8 & 2 & 2 & 3 & $33 . \%$ & $20 \%$ & $37.5 \%$ & $5.6 \%$ & $3.6 \%$ & $6 \%$ \\
\hline Total & 50 & 150 & 50 & 26 & 95 & 27 & - & - & - & $52 \%$ & $63.3 \%$ & $54 \%$ \\
\hline
\end{tabular}


Table 2 Evaluation of pregnant women categorized by trimester of pregnancy with deference to $\mathrm{Hb}$, serum ferritin, serum iron, TIBC, transferrin saturation, $\mathrm{MCV}$ and $\mathrm{MCH}$.

\begin{tabular}{|l|l|l|l|l|l|l|}
\hline & \multicolumn{2}{|l|}{$\begin{array}{c}\text { First trimester } \\
(\mathrm{n}=50)\end{array}$} & \multicolumn{2}{c|}{$\begin{array}{c}\text { Second trimester } \\
(\mathrm{n}=150)\end{array}$} & \multicolumn{2}{c|}{$\begin{array}{c}\text { Third trimester } \\
(\mathrm{n}=50)\end{array}$} \\
\hline Variable & Mean & SD & Mean & SD & Mean & SD \\
\hline Hb gm/dl & 9.602 & 0.87 & 8.48 & 1.24 & 9.18 & 1.28 \\
\hline serum ferritin & 14.82 & 5.75 & 18.12 & 6.87 & 19.23 & 7.56 \\
\hline Serum iron & 69.66 & 33.04 & 52.23 & 26.34 & 72.45 & 35.66 \\
\hline TIBC & 271.34 & 43.14 & 244.33 & 26.22 & 263.67 & 35.98 \\
\hline Transferin saturation & 25.50 & 9.22 & 20.21 & 7.24 & 26.34 & 10.67 \\
\hline MCV & 71.23 & 16.53 & 66.43 & 13.45 & 71.43 & 11.57 \\
\hline MCH & 16.74 & 2.58 & 20.64 & 4.56 & 17.45 & 1.76 \\
\hline
\end{tabular}

Fig 1 Scatter plot of serum ferritin and $\mathrm{Hb}$ Pearson correlation $\mathrm{P}=0.01$

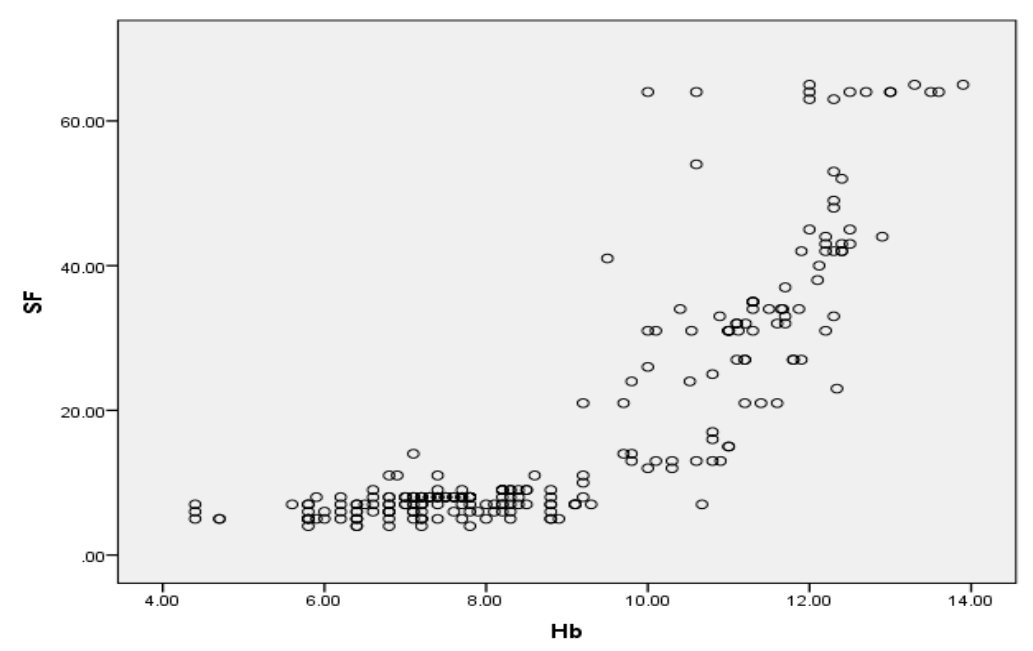

Fig 2 Scatter plot of serum ferritin and MCV Pearson correlation $\mathrm{P}=0.01$

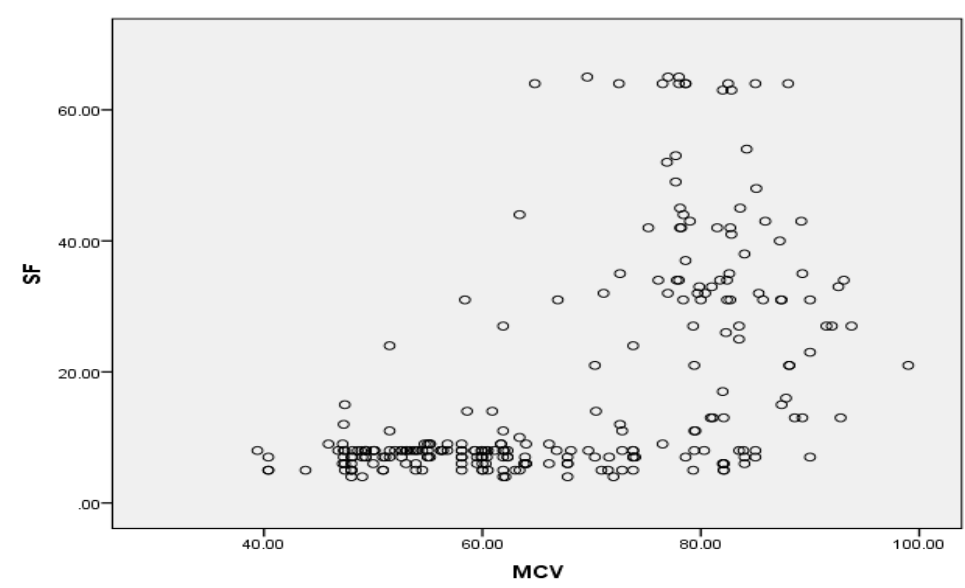


Fig 3 Scatter plot of serum ferritin and $\mathrm{MCH}$ Pearson correlation $\mathrm{P}=0.01$

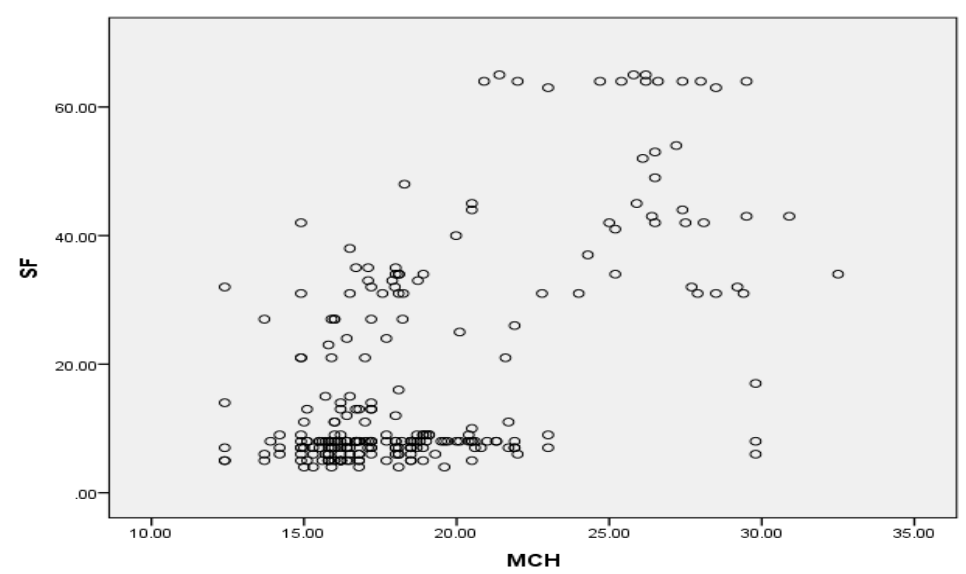

\subsection{Microcytic, macrocytic and normocytic anemia in our studied population}

After finding the percent ratio of anemic patients in different trimesters next, we found out the ratio of different types of anemia in affected population. The data shown in (table 3) represented the occurrence of micro- $(80.2 \%)$, macro- (14.9\%) and normocytic anemia $(4.9 \%)$ in 148anemicpregnant women of different age group belongs to different region of Swat District. In first trimester the number of patients; 73.0, 7.5, and 19.5\% were found micro- , macro- and normocytic, respectively. In the second trimester it was $85.5,3.5$ and $11.5 \%$; micro- , macro- and normocytic, respectively. In $3^{\text {rd }}$ trimester number of patients was similar to the first group except only $2.8 \%$ increase in normocytic anemia.

Table 3 shows microcytic, macrocytic and normocytic anemia in different trimester

\begin{tabular}{|l|l|l|l|l|l|}
\hline Trimester & No of cases & Anemic & $\begin{array}{l}\text { Microcytic } \\
\text { anemia }\end{array}$ & $\begin{array}{l}\text { Macrocytic } \\
\text { anemia }\end{array}$ & $\begin{array}{l}\text { Normocytic } \\
\text { anemia }\end{array}$ \\
\hline $1^{\text {st }}$ Trimester & 50 & 26 & $19(73 \%)$ & $2(7.5 \%)$ & $5(19.5 \%)$ \\
\hline $2^{\text {nd }}$ Trimester & 150 & 95 & $81(85 \%)$ & $3(3.5 \%)$ & $11(11.5 \%)$ \\
\hline $3^{\text {rd }}$ Trimester & 50 & 27 & $19(70.3 \%)$ & $2(7.4 \%)$ & $6(22.3 \%)$ \\
\hline Total & 250 & 148 & $119(80.2 \%)$ & $7(4.9 \%)$ & $22(14.9 \%)$ \\
\hline
\end{tabular}




\subsection{Classification of IDA severity in studied population}

Severity of IDA was classified into severe and moderate groups on the basis of serum ferritin level. The patients suffered from moderate IDA were 61.5 , while $38.5 \%$ were found with severe level (Table 4).

Table 4 shows percent severity of IDA

\begin{tabular}{|l|c|c|}
\hline Severity & $\begin{array}{c}\text { No of patient } \\
\text { (n) }\end{array}$ & $\begin{array}{c}\text { Percentage } \\
(\%)\end{array}$ \\
\hline Moderate serum ferritin $8-12 \mu \mathrm{g} / \mathrm{L}$ & 91 & $61.5 \%$ \\
\hline Severe serum ferritin $<8 \mu \mathrm{g} / \mathrm{L}$ & 57 & $38.5 \%$ \\
\hline
\end{tabular}

\section{Discussion}

In this study, we described that imbalance diet and lack of iron supplementation in pregnancy or in daily routine life develops the risk of IDA. High incidence rates of IDA with 75, 72 , and $71 \%$ in different trimesters $\left(1^{\text {st }}, 2^{\text {nd }}\right.$ and $\left.3^{\text {rd }}\right)$; in $16-20$ age group indicated the poor diet quality of pregnant women living in Swat District. The higher rank of anemia is found in developing world where its factors are numerous [14]. Pregnant women using Iron supplementations seem to be more protective from severe IDA. In our study the highest prevalence of the anemia was found, $75 \%$ in age group of 16-20 years in the first trimester reflected the lack of regular medical checkup for young married women. Iron lost in fertile women is due to menstruation, breast feeding and pregnancy [15]. Most of patients of 16-20 years old visited clinics after feeling sever fatigue and body pain were found pregnant. Similarly, the highest occurrences of anemia were found $78.2 \%$ in the age from $26-30$ years followed by $78.2 \%$ in the age group 36-40 years compared to the other age groups in the second trimester. The occurrences of microcytic, macrocytic and normocytic anemia are $80.2 \%, 14.9 \%$ and $4.9 \%$ in population of 250 pregnant women of different age group belongs to different region of Swat District.

\subsection{Conclusion}

In our study the prevalence of IDA in third trimester is lower as compared to the first and second trimester. The reason for decline in IDA might be frequent clinic consultations. In 
addition, taking iron supplementation during last stages of gestation, and better care possibly reduced the chances of IDA.

\subsection{Recommendation}

Mother and child health centers in Swat District need to focus on the importance of iron supplementation and balance diets for pregnant and lactating mothers. In our study, high incidence of anemia in population gives directions for further investigations to determine the risk factors. Moreover, we also suggest for local development of the nutritional interference act programs pay attention in direction of expected women to combat IDA.

\subsection{Acknowledgment}

We are thankful to the medical superintendent (MS) of Sabeel Surgical and Maternity Home Swat District, Khyber Pakhtunkhwa, Pakistan for their cooperation in data collection.

\subsection{Conflict of interest}

All authors are agreed upon all the section of this research article and there is no conflict of interest.

\section{References}

1. Hentze MW, Muckenthaler MU, Galy B, Camaschella C. Two to tango: regulation of mammalian iron metabolism. Cell 2010;142:24-38.

2. Shill KB, Karmakar P, Kibria G, Das A, Rahman MA, Hossain MS, et al. Prevalence of iron-deficiency anaemia among university students in Noakhali region, Bangladesh. J Health PopulNutr. 2014;32:103-110.

3. Sirdah MM, Yaghi A, Yaghi AR. Iron deficiency anemia among kindergarten children living in the marginalized areas of Gaza Strip, Palestine. Rev Bras HematolHemoter. 2014;36:132-138. 
4. Kassebaum NJ, Jasrasaria R, Naghavi M, Wulf SK, Johns N, Lozano R, et al. A systematic analysis of global anemia burden from 1990 to 2010. Blood. 2014;30(123):615624.

5. Johnson TA. Anemia. In: Luesley DM, Baker PN, editors. Obstetrics and Gynaecology An evidencebased text for mrcog. 2nd ed. London: Hodderarnold; 2010. p. 139-43

6. A. Abriha, M. E. Yesuf, and M. M. Wassie, "Prevalence and associated factors of anemia among pregnant women of Mekelle town: a cross sectional study," BMC Research Notes, vol. 7, article 888, 2014.

7. Haider BA, Olofin I, Wang M, Spiegelman D, Ezzati M, Fawzi WW. Anaemia, prenatal iron use, and risk of adverse pregnancy outcomes: systematic review and meta-analysis. BMJ. 2013;346: f3443.

8. Kefiyalew F, Zemene E, Asres Y, Gedefaw L. Anemia among pregnant women in Southeast Ethiopia: prevalence, severity and associated risk factors. BMC Res Notes. 2014;7:771.

9. Bener A, Kamal M, Bener H, Bhugra D. Higher prevalence of iron deficiency as strong predictor of attention deficit hyperactivity disorder in children. Ann Med Health Sci Res. 2014;4(Suppl 3):291-297.

10. Kassebaum NJ, Jasrasaria R, Naghavi M, Wulf SK, Johns N, Lozano R, et al. A systematic analysis of global anemia burden from 1990 to 2010. Blood. 2014;123: 615-624.

11. Dainty JR, Berry R, Lynch SR, Harvey LJ, Fairweather-Tait SJ. Estimation of dietary iron bioavailability from food iron intake and iron status. PLoS One. 2014;9:e111824.

12. Breyman C. Iron deficiency in pregnancy. Seminars in hematol;2015; vol 52 (4) 339-347.

13. Sushma P, Naaz A, Sarma DVHS, Shireesha R. A study on serum iron, TIBC and nutritional status in III trimester pregnancy. Int J Sci Res Publ 2014;4(12):1-3.

14. Ivan EA, Mangaiarkkarasi A. Evaluation of anaemia in booked antenatal mothers during the last trimester. J Clin Diagn Res. 2013;7(11): 248724 90. doi :10. 7860 /JCDR /2013 / 6370.3586 .

15. Mohammad Reza Sharif, Davood Kheirkhah, et al. The relationship between iron deficiency and febrile convulsion: a case-control study. Global Journal of Health Science. Global Journal of Health Science. 2016. Vol 8 (2)185-189.

(C) 2017 by the authors; licensee Preprints, Basel, Switzerland. This article is an open access article distributed under the terms and conditions of the Creative Commons by Attribution (CC-BY) license (http://creativecommons.org/licenses/by/4.0/). 